\title{
According to the Binary Number Base System, Are the Square Roots of Two Numbers also Significant in Biochemistry?
}

\author{
Tahir Ölmez \\ Social Sciences Dept., Selçuk University, Konya, Turkey \\ Email: bsonmez3@gmail.com, tolmez123@yahoo.com
}

How to cite this paper: Ölmez, T. (2021) According to the Binary Number Base System, Are the Square Roots of Two Numbers also Significant in Biochemistry? Open Access Library Journal, 8: e7122.

https://doi.org/10.4236/oalib.1107122

Received: December 29, 2020

Accepted: January 24, 2021

Published: January 27, 2021

Copyright $\odot 2021$ by author(s) and Open Access Library Inc.

This work is licensed under the Creative Commons Attribution International License (CC BY 4.0).

http://creativecommons.org/licenses/by/4.0/

\begin{abstract}
According to Quantum Perspective Model, this article researches whether there is a link between the square root of two numbers and the genetic codes. At first, when the digits of the square root of two numbers after the comma are converted from decimal (10) number base system to binary (2) number base system, it corresponds to nucleotide bases. Secondly, the results obtained by this way are expressed as nucleotide bases (A, T, C, G, and U): (A) Adenine, (T) Thymine, (C) Cytosine, (G) Guanine, (U) Uracil. From this point of view, when the first two hundred digits of the square root of two numbers after the comma were calculated. Thirdly, the search result is similar to DANIO RERIO, and even Timema, after the NCBI (National Biotechnology Information Center) searched this sequence [GGATGTCTATTGAGTGACAA]. Fourthly, the genetic codes of Zebra fish have been proven to be very similar to human genetic codes. Lastly, Even Timema reproduces asexually. From this perspective not only the square root of two numbers is irrational number but also Timema has abnormal sexual reproduction. In sum, the relationship between the square root of two in mathematical science and the genetic codes also shed lights on Biochemistry.
\end{abstract}

\section{Subject Areas}

Mathematics, Number Theory

\section{Keywords}

Quantum Perspective Model, Danio Rerio, Binary Number Base System, The Square Root of Two, Timema 


\section{Introduction and Calculation of the Square Root of Two Numbers [1] from Decimal Base System (10) to Binary Base System (2) and Binary Base System (2) to Decimal Base System (10)}

The relationships between numbers and genetic codes are not only researched with pi numbers but also researched with the golden ratio numbers, too [2]. The name of this relationship research is called Quantum Perspective Model by Kevser Köklü [3]. Also, according to this model, this paper attempts to search the relationships between the square root of the number two and the genetic codes (see Table 1).

\section{Methods and Discussion}

The chemical structures of bases include Carbon (C), Nitrogen (N), Oxygen ( $\mathbf{O})$, and Hydrogen $(\mathrm{H})$. Calculation of bases with chemical atoms (See also Table 2) (Ölmez T, 2020) [4].

Table 1. The representation of decimal numbers in the binary base and the representation of binary base numbers to the decimal base.

\begin{tabular}{|c|c|c|c|c|c|c|c|c|c|c|}
\hline DECIMAL & 1 & 2 & 3 & 4 & 5 & 6 & 7 & 8 & 9 & 10 \\
\hline$B I N A R Y$ & 01 & 10 & 11 & 100 & 101 & 110 & 111 & 1000 & 1001 & 1010 \\
\hline DECIMAL & 11 & 12 & 13 & 14 & 15 & 16 & 17 & 18 & 19 & 20 \\
\hline$B I N A R Y$ & 1011 & 1100 & 1101 & 1110 & 1111 & 10000 & 10001 & 10010 & 10011 & 10100 \\
\hline DECIMAL & 21 & 22 & 23 & 24 & 25 & 26 & 27 & 28 & 29 & 30 \\
\hline$B I N A R Y$ & 10101 & 10110 & 10111 & 11000 & 11001 & 11010 & 11011 & 11100 & 11101 & 11110 \\
\hline DECIMAL & 31 & 32 & 33 & 34 & 35 & 36 & 37 & 38 & 39 & 40 \\
\hline$B I N A R Y$ & 11111 & 100000 & 100001 & 100010 & 100011 & 100100 & 100101 & 100110 & 100111 & 101000 \\
\hline DECIMAL & 41 & 42 & 43 & 44 & 45 & 46 & 47 & 48 & 49 & 50 \\
\hline$B I N A R Y$ & 101001 & 101010 & 101011 & 101100 & 101101 & 101110 & 101111 & 110000 & 110001 & 110010 \\
\hline DECIMAL & 51 & 52 & 53 & 54 & 55 & 56 & 57 & 58 & 59 & 60 \\
\hline$B I N A R Y$ & 110011 & 110100 & 110101 & 110110 & 110111 & 111000 & 111001 & 111010 & 111011 & 111100 \\
\hline DECIMAL & 61 & 62 & 63 & 64 & 65 & 66 & 67 & 68 & 69 & 70 \\
\hline$B I N A R Y$ & 111101 & 111110 & 111111 & 1000000 & 1000001 & 1000010 & 100011 & 1000100 & 1000101 & 1000110 \\
\hline DECIMAL & 71 & 72 & 73 & 74 & 75 & 76 & 77 & 78 & 79 & 80 \\
\hline BINARY & 1000111 & 1001000 & 1001001 & 1001010 & 1001011 & 1001100 & 1001101 & 1001110 & 1001111 & 1010001 \\
\hline DECIMAL & 81 & 82 & 83 & 84 & 85 & 86 & 87 & 88 & 89 & 90 \\
\hline$B I N A R Y$ & 1010001 & 1010010 & 1010011 & 1010100 & 1010101 & 1010110 & 1010111 & 1011000 & 1011001 & 1011010 \\
\hline DECIMAL & 91 & 92 & 93 & 94 & 95 & 96 & 97 & 98 & 99 & 100 \\
\hline$B I N A R Y$ & 1011011 & 1011100 & 1011101 & 1011110 & 1011111 & 1100000 & 1100001 & 1100010 & 1100011 & 1100100 \\
\hline
\end{tabular}

Table 2. Representation of nucleotide bases (A, T, C, G and U) in chemical atoms.

\begin{tabular}{cccccc}
\hline ATOMS/NUCLEOTIDE BASES & $\boldsymbol{C}=\boldsymbol{6}$ & $\boldsymbol{H}=\boldsymbol{1}$ & $\boldsymbol{O}=\boldsymbol{8}$ & $\boldsymbol{N}=\boldsymbol{7}$ & SUM \\
\hline ADENINE: $\mathrm{C}_{5} \mathrm{H}_{5} \mathrm{~N}_{5}$ & 5 & 5 & - & 5 & 70 \\
THYMINE: $\mathrm{C}_{5} \mathrm{H}_{6} \mathrm{~N}_{2} \mathrm{O}_{2}$ & 5 & 6 & 2 & 2 & 66 \\
CYTOSINE: $\mathrm{C}_{4} \mathrm{H}_{5} \mathrm{~N}_{3} \mathrm{O}_{1}$ & 4 & 5 & 1 & 3 & 64 \\
GUANINE: $\mathrm{C}_{5} \mathrm{H}_{5} \mathrm{~N}_{5} \mathrm{O}_{1}$ & 5 & 5 & 1 & 5 & 78 \\
URACIL: $\mathrm{C}_{4} \mathrm{H}_{4} \mathrm{~N}_{2} \mathrm{O}_{2}$ & 4 & 4 & 2 & 2 & 58 \\
\hline
\end{tabular}


The atomic numbers of them: Carbon $(\mathbf{C}): 6$, Nitrogen $(\mathbf{N}): 7$, Oxygen $(\mathbf{O}): 8$, Hydrogen (H): 1 (Wieser E M et al., 2013) [5]. The chemical structures of bases

(A, T, C, G, and U) are shown below (Ölmez T, 2020) [4].
(A) Adenine: $\mathrm{C}_{5} \mathrm{H}_{5} \mathrm{~N}_{5}: 70$;
(T) Thymine: $\mathrm{C}_{5} \mathrm{H}_{6} \mathrm{~N}_{2} \mathrm{O}_{2}: 66$,
(C) Cytosine: $\mathrm{C}_{4} \mathrm{H}_{5} \mathrm{~N}_{3} \mathrm{O}_{1}: 64$,
(G) Guanine: $\mathrm{C}_{5} \mathrm{H}_{5} \mathrm{~N}_{5} \mathrm{O}_{1}:$ 78, and
(U) Uracil: $\mathrm{C}_{4} \mathrm{H}_{4} \mathrm{~N}_{2} \mathrm{O}_{2}: 58$
(Lodish $\mathrm{H}$ et al., 2018) [6].

Also in this research, genetic codes were used as a new formula (Nirenberg et al., 1965) [7] just like as (A, T, C, G, and U). (A) Adenine, (T) Thymine, (C) Cytosine, (G) Guanine, (U) Uracil. Before this work, the fourteen groups of Pi number can be shown as:

Continuous UTA's by Kevser Köklü [3]. Also, another favorite sample of this research is done with velocity of light numbers by Kevser Köklü again [8]. Lastly, in another article with identical cis regulatory elements examined the links between the Golden Ratio numbers [2]. After all these studies, the square root of the two numbers and the genetic codes are now being investigated in relation to the Quantum Perspective Model.

\section{Calculation of the Square Root of Two Numbers and Genetic Codes}

The first two hundred digits of the square root of two after the comma are here:

1.4142135623730950488016887242096980785696718753769480731766797 3799073247846210703885038753432764157273501384623091229702492483 6055850737212644121497099935831413222665927505592755799950501152 7820605714701095599716059702745345968620147285174186408891986095 5232923048430871432145083976260362799525140.

At first, the first two digits after the comma were taken each time. For example, $41,42,13,56,23,73,09,50,48 \ldots$ and so on. Then these numbers are found in the binary number system in Table 1 . (For instance, “41", 101001 and so on). Secondly, convert these binary numbers to decimal number base (For instance, " 41 " $101001 ; 10=2,100=4$ and $1=1$ ). Thirdly, all decimal numbers are subjected to the addition process, respectively. $(2+4+1=7)$. All of the first result of the addition is " 75 ". Just like as in Guanine (G): 78 (See also Table 2).

\begin{tabular}{|c|c|c|c|c|c|c|c|c|}
\hline 41 & 42 & 13 & 56 & 23 & 73 & 09 & 50 & 48 \\
\hline 101001 & 101010 & 1101 & 111000 & 10111 & 1001001 & 1001 & 110010 & 110000 \\
\hline 101001 & 101010 & 1101 & 111000 & 10111 & 1001001 & 1001 & 110010 & 110000 \\
\hline $2+4+1$ & $2+2+2$ & $+1+5$ & $+3+8$ & $+2+7$ & $+4+4+1$ & $+2+1$ & $+1+4+2$ & $+1+16=75(\mathrm{G})$ Guanine: 78 \\
\hline 80 & 16 & 88 & 72 & 42 & 09 & 69 & & \\
\hline 1010001 & 10000 & 1011000 & 1001000 & 101010 & 1001 & 1000101 & & \\
\hline $2+8+1$ & +16 & $5+8$ & $4+8$ & $+2+2+2$ & +9 & $+8+5=8$ & (G) Guanine & 78 \\
\hline
\end{tabular}




\section{Continued}

\begin{tabular}{|c|c|c|c|c|c|c|c|}
\hline 80 & 78 & 56 & 96 & \multicolumn{4}{|l|}{71} \\
\hline 1010001 & 1001110 & 111000 & 1100000 & \multicolumn{4}{|l|}{1000111} \\
\hline 1010001 & 1001110 & 111000 & 1100000 & \multicolumn{4}{|l|}{1000111} \\
\hline $2+8+1$ & $+4+3+2$ & $+3+8$ & $+1+32$ & \multicolumn{4}{|c|}{$+8=72(\mathrm{~A})$ Adenine: 70} \\
\hline \multicolumn{2}{|c|}{71 (MORE) 87} & 53 & 76 & 94 & \multicolumn{3}{|l|}{80} \\
\hline 111 & 1010111 & 110101 & 1001100 & 1011110 & \multicolumn{3}{|l|}{1010001} \\
\hline $7+$ & $2+2+7$ & $+6+5$ & $+4+12$ & $+5+3+2$ & \multicolumn{3}{|c|}{$+2+8+1=66(\mathrm{~T})$ Thymine: 66} \\
\hline 73 & 17 & 66 & 79 & 73 & 79 & 90 & \\
\hline 1001001 & 10001 & 1000010 & 1001111 & 1001001 & 1001111 & 1011010 & \\
\hline 1001001 & 10001 & 1000010 & 1001111 & 1001001 & 1001111 & 10110 & \\
\hline \multicolumn{2}{|c|}{90 (MORE) 73} & 24 & 78 & 46 & 21 & 07 & 03 \\
\hline 1011010 & 1001001 & 11000 & 1001110 & 101110 & 10101 & 111 & 1011000 \\
\hline 10 & 1001001 & 11000 & 1001110 & 101110 & 10101 & 111 & 1011000 \\
\hline 2 & $+4+4+1$ & $+1+8$ & $+4+3+2$ & $2+3+2$ & $2+5$ & +7 & $5+8=66(\mathrm{~T})$ Thymine: 66 \\
\hline 50 & 38 & 75 & 34 & \multicolumn{4}{|l|}{32} \\
\hline 110010 & 100110 & 1001011 & 100010 & \multicolumn{4}{|l|}{100000} \\
\hline 110010 & 100110 & 1001011 & 100010 & \multicolumn{4}{|l|}{100000} \\
\hline $1+4+2$ & $+2+1+2$ & $+4+2+3$ & $+8+2$ & \multicolumn{4}{|c|}{$+32=63(\mathrm{C})$ Cytosine: 64} \\
\hline 76 & 41 & 57 & 27 & 35 & 01 & 38 & 46 \\
\hline 1001100 & 101001 & 111001 & 11011 & 100011 & 01 & 100110 & 101110 \\
\hline 23 & 09 & 12 & 29 & 70 & 24 & 92 & 48 \\
\hline 10111 & 1001 & 1100 & 11101 & 1000110 & 11000 & 1011100 & 110000 \\
\hline 10111 & 1001 & 1100 & 11101 & 1000110 & 11000 & 1011100 & 110000 \\
\hline $2+7$ & $+2+1$ & $+1+4$ & $+3+2+1$ & $+8+6$ & $+1+8$ & $+5+1+4$ & $+1+16=73(\mathrm{~A})$ Adenine: 70 \\
\hline 36 & 05 & 58 & 50 & 73 & 72 & 12 & $64^{*}$ \\
\hline 100100 & 101 & 111010 & 110010 & 1001001 & 1001000 & 1100 & 1000000 \\
\hline 100100 & 101 & 111010 & 110010 & 1001001 & 1001000 & 1100 & $10000 \underline{00}$ \\
\hline $4+4+$ & $+2+1$ & $+3+2+2$ & $+1+4+2$ & $+4+4+1$ & $4+8$ & $+1+4$ & +16 (“00” EMPTY $): 67$ (T) Thymine: 66 \\
\hline 41 & 21 & 49 & 70 & 99 & 93 & 58 & \\
\hline 101001 & 10101 & 110001 & 1000110 & 1100011 & 1011101 & 111010 & \\
\hline 101001 & 10101 & 110001 & 1000110 & 1100011 & 1011101 & 111010 & \\
\hline $2+4+1$ & $+2+5$ & $+1+8+1$ & $+8+6$ & $+1+8+2$ & $+2+3+5$ & $+3+2+2=$ & $=66(\mathrm{~T})$ Thymine: 66 \\
\hline 31 & 41 & $32^{*}$ & 22 & 66 & 59 & 27 & 50 \\
\hline 11111 & 101001 & $1000 \underline{00}$ & 10110 & 1000010 & 111011 & 11011 & 110010 \\
\hline 11111 & 101001 & $1000 \underline{00}$ & 10110 & 1000010 & 111011 & 11011 & 110010 (“OO”EMPTY $)$ \\
\hline $3+3+1$ & $+2+4+1$ & +16 & $+2+6$ & $+16+2$ & $3+2+3$ & $+1+2+3$ & $+1+4+2=77(\mathbf{G})$ Guanine: 78 \\
\hline 55 & 92 & 75 & 57 & 99 & 95 & 05 & 01 \\
\hline 110111 & 1011100 & 1001011 & 111001 & 1100011 & 1011111 & 101 & 1111 \\
\hline 110111 & 1011100 & 1001011 & 111001 & 1100011 & 1011111 & 101 & 1111 \\
\hline $6+7$ & $+5+1+4$ & $+4+2+3$ & $+3+4+1$ & $+1+8+2$ & $+2+3+3+1$ & $12+1$ & $3+3=70(\mathrm{~A})$ Adenine: 70 \\
\hline
\end{tabular}




\begin{tabular}{|c|c|c|c|c|c|c|c|c|c|}
\hline \multicolumn{10}{|l|}{ Continued } \\
\hline 27 & 82 & 06 & 05 & 71 & 47 & 01 & 09 & 55 & 99 \\
\hline 11011 & 1010010 & 110 & 101 & 1000111 & 101111 & 01 & 1001 & 110111 & 1100011 \\
\hline 11011 & 1010010 & 110 & 101 & 1000111 & 101111 & 01 & 1001 & 110111 & 11000 \\
\hline $6+3$ & $2+4+2$ & $+1+2$ & $+2+1$ & $+8+7$ & $2+3+3$ & +1 & +9 & $+6+7$ & $1+8=78(\mathbf{G})$ Guanine: 78 \\
\hline \multicolumn{2}{|c|}{99 (MORE) 71} & 60 & 59 & 70 & 27 & \multicolumn{4}{|l|}{45} \\
\hline 1100011 & 1000111 & 111100 & 111011 & 1000110 & 11011 & \multicolumn{4}{|l|}{101101} \\
\hline 11 & 1000111 & 111100 & 111011 & 1000110 & 11011 & \multicolumn{4}{|l|}{101101} \\
\hline 8 & $8+7$ & $+3+1+4$ & $+3+2+3$ & $8+7$ & $1+2+3$ & \multicolumn{4}{|c|}{$+2+3+1=66(\mathrm{~T})$ Thymine: 66} \\
\hline 34 & 59 & 68 & 62 & 01 & 47 & 28 & 51 & 74 & 18 \\
\hline 100010 & 111011 & 1000100 & 111110 & 01 & 101111 & 11100 & 110011 & 1001010 & 10010 \\
\hline 100010 & 111011 & 1000100 & 111110 & 01 & 101111 & 11100 & 110011 & 1001010 & 10010 \\
\hline $8+2$ & $3+2+3$ & $8+4$ & $+3+3+2$ & +1 & $+2+3+3$ & $+3+4$ & $+1+4+3$ & $+4+2+2$ & $+4+2=76(\mathrm{G})$ Guanine: 78 \\
\hline $64^{*}$ & 08 & 89 & 19 & 86 & 09 & \multicolumn{4}{|l|}{55} \\
\hline $10000 \underline{00}$ & 1000 & 1011001 & 10011 & 1010110 & 1001 & \multicolumn{4}{|c|}{110111 (“OO”EMPTY) } \\
\hline $10000 \underline{00}$ & 1000 & 1011001 & 10011 & 1010110 & 1001 & \multicolumn{4}{|c|}{110111} \\
\hline 16 & $+8+$ & \multicolumn{2}{|c|}{$2+1+2+14+3$} & $+2+2+6$ & +9 & \multicolumn{4}{|c|}{$+6+7=69$ (A) Adenine: 70} \\
\hline 23 & 29 & 23 & 04 & 84 & 30 & 87 & \multicolumn{3}{|c|}{14} \\
\hline 10111 & 11101 & 10111 & 100 & 1010100 & 11110 & 1010111 & \multicolumn{3}{|l|}{1110} \\
\hline 10111 & 11101 & 10111 & 100 & 1010100 & 11110 & 1010111 & \multicolumn{3}{|l|}{1110} \\
\hline $2+7$ & $+3+2+1$ & $+2+7$ & +4 & $+2+2+4$ & $+3+6$ & $2+2+7$ & \multicolumn{3}{|c|}{$+3+2=61(\mathrm{C})$ Cytosine: 64} \\
\hline 32 & 14 & 50 & 83 & \multicolumn{6}{|l|}{97} \\
\hline 100000 & 1110 & 110010 & 1010011 & \multicolumn{6}{|l|}{1100001} \\
\hline 100000 & 1110 & 110010 & 1010011 & \multicolumn{6}{|l|}{1100001} \\
\hline 32 & $+3+2$ & $+1+4+2$ & $+2+4+3$ & \multicolumn{6}{|c|}{$+1+16+1=71(\mathrm{~A})$ Adenine: 70} \\
\hline 62 & 60 & 36 & 27 & 99 & 52 & 51 & \multicolumn{3}{|l|}{40} \\
\hline 111110 & 111100 & 100100 & 11011 & 1100011 & 110100 & 110011 & \multicolumn{3}{|l|}{101000} \\
\hline 111110 & 111100 & 100100 & 11011 & 1100011 & 110100 & 110011 & \multicolumn{3}{|l|}{101000} \\
\hline $3+3+2$ & $+7+4$ & $+4+4$ & $+1+2+3$ & $+1+8+2$ & $+6+4$ & $+1+4+3$ & \multicolumn{3}{|c|}{$+2+8=72(\mathrm{~A})$ Adenine: 70} \\
\hline
\end{tabular}

This sequence can be shown as [GGATGTCTATTGAGTGACAA]. Let me try to explain this sequence with the "Quantum Perspective Model." For example, The second groups of the square root of two after comma equal to Guanine (G): 80 with two more of Hydrogen bonds (H: 1). (Remember, See Table 2; Guanine (G): 78) This result could be the meaning of the square root of two sequence in groups [GGATGTCTATTGAGTGACAA]. The tenth groups of the square root of two after the comma is regarded as Thymine $(T)$ with the one more of Hydrogen bond (H: 1). (Because the deviations in the calculation of the square root of two numbers can be derived from the Adenine (A) - Thymine (T) Hydrogen bonds because of Adenine (A) pairs with Thymine (T) by two hydrogen bonds. Cytosine (C) - Guanine (G) pairs with by three hydrogen bonds [3]. The reason for the lack of hydrogen bonds: Hydrogen bonding is a very versatile attraction. (Ölmez T, 2020) [3] Hydrogen bonds are relatively weak and easily broken by increasing hardness (Farrell, 2010) [9]. During the calculation, the "EMPTY" numbers " $O O^{\prime}$ " are disregarded. According to the number-based system, the number " 00 " has no value, neither in the decimal nor in 
the binary-based system. According to binary encoding base system, on the case of current not passing, this means 0 (zero). That's why, it can be the reason of disregardence of " $E M P T Y$ " " $O O$ " numbers. Please, ignore the " $E M P T Y$ " numbers " $O O$ " for calculation especially in tenth, twelwth and seventh groups.

\section{Results}

After searching the square root of two numbers result in

[GGATGTCTATTGAGTGACAA] The National Center for Biotechnology Information (NCBI) databases, some conceptual relationships can be found with bony fish [10]. Types of bony fishes are based on DANIO RERIO (Zebra fish). (See Figure 1). Types of other living creatures are potato, dog, blunt-snouted clingfish, milk fish, Georgia icefish, gold fish, pinocone soldier fish, Indian glassy fish, house mouse, golden spiny mouse, Southern grassphopper mouse, South leopard coralgroupher, river trout, chimpanzee, Timema cristinae (insect), Timema monikensis, Timema poppensis, Chinook salmon, large flying fox, Danio khathit, Danio aesculapii, Zebra finch, small spotted catshark, pig and (See Figure 2). Danio khathit and Danio aesculapii have a similar genetic

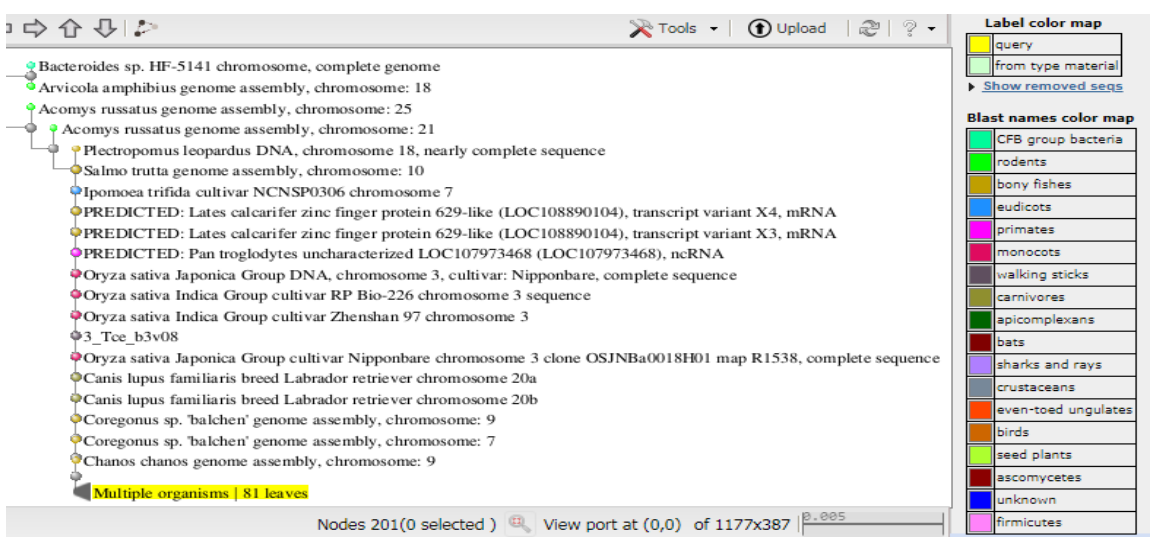

Figure 1. The NCBI (National Biotechnology Information Center) result blast tree view widget for "GGATGTCTATTGAGTGACAA" nucleotide sequence [13].

\begin{tabular}{|c|c|c|c|c|c|c|c|c|}
\hline PREDICTED Lates calcarifer zinc finger protein 629-ike (LOC 108890104), transcript variant X4, $\mathrm{mRNA}$ & barramundip. & 36.2 & 36.2 & $90 \%$ & 9.1 & $100.00 \%$ & 2167 & 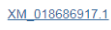 \\
\hline PREDICTED: Lates calcarifer zinc finger protein 629--ike (LOC 108890104), transcript variant X3, $\mathrm{mRNA}$ & barramundip.... & 36.2 & 36.2 & $90 \%$ & 9.1 & $100.00 \%$ & 3742 & 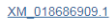 \\
\hline PREDICTED: Pan troglodytes uncharacterized LOC 107973468 (LOC 107973468), ncRNA & chimpanzee & 36.2 & 36.2 & $90 \%$ & 9.1 & $100.00 \%$ & 2665 & $\underline{X R \quad 001715778.1}$ \\
\hline Oryza sativa Japonica Group DNA chromosome 3, cultvar: Nipponbare, complete sequence & Japanose rice & 36.2 & 36.2 & $90 \%$ & 9.1 & $100.00 \%$ & 36413819 & AP014959.1 \\
\hline Oryza sativa Indica Group cultivar RP Bio-226 chromosome 3 sequence & long-grained. & 36.2 & 36.2 & $90 \%$ & 9.1 & $100.00 \%$ & 9504267 & CP012611.1 \\
\hline Oryza sativa Indica Group cultivar Zhenshan 97 chromosome 3 & long-grained. & 36.2 & 36.2 & $90 \%$ & 9.1 & $100.00 \%$ & 39636162 & $\underline{\text { CP056054.1 }}$ \\
\hline 3-Tee b3v08 & Iimema cristi... & 36.2 & 36.2 & $90 \%$ & 9.1 & $100.00 \%$ & 821 & OC379152.1 \\
\hline Aconys russatus genome assemby, chromosome: 21 & golden spiny_... & 36.2 & 66.4 & $95 \%$ & 9.1 & $100.00 \%$ & 61132863 & $\underline{L R 877232.1}$ \\
\hline Oryza sativa Japonica Group cultivar Nipponbare chromosome 3 clone OSJNBa0018H01 map R1538. & . Japanese rice & 36.2 & 36.2 & $90 \%$ & 9.1 & $100.00 \%$ & 142712 & AC087181.9 \\
\hline Canis lupus familiaris breed Labrador retriever chromosome $20 \mathrm{a}$ & dog & 34.2 & 34.2 & $85 \%$ & 36 & $100.00 \%$ & 58324418 & $\underline{\text { CP050571.1 }}$ \\
\hline Canis lupus familiaris breed L abrador retriever chromosome $20 \mathrm{~b}$ & deg & 34.2 & 34.2 & $85 \%$ & 36 & $100.00 \%$ & 58321546 & CP0506311 \\
\hline Coregonus sp. 'balchen' genome assembly. chromosome: 9 & Coregonus s... & 34.2 & 34.2 & $85 \%$ & 36 & $100.00 \%$ & 65193448 & $\underline{L R 778261.1}$ \\
\hline Coregonus $\mathrm{S}$ ' 'balchen' genome assembly. chromosome: 7 & Coregonus. & 34.2 & 34.2 & $85 \%$ & 36 & $100.00 \%$ & 65391737 & LR7782591 \\
\hline Chanos chanos genome assembly. chromosome: 9 & milkfish & 34.2 & 34.2 & $85 \%$ & 36 & $100.00 \%$ & 43790413 & $\underline{L R 697114.1}$ \\
\hline Chanos chanos genome assembly. chromosome 6 & milkfish & 34.2 & 34.2 & $85 \%$ & 36 & $100.00 \%$ & 50300218 & $\underline{\text { LR697111.1 }}$ \\
\hline PREDICTED. Salmo truta 5-hydroxytyyplamine receptor 3A-ike (LOC 115148698), MRNA & tiver trout & 34.2 & 34.2 & $85 \%$ & 36 & $100.00 \%$ & 3793 & $\underline{X M}-029690828.1$ \\
\hline Myrpristis murdjän genome assembly, chromosome: 6 & pinecone sol. & 34.2 & 34.2 & $85 \%$ & 36 & $100.00 \%$ & 35357120 & $\underline{\text { LR597555.1 }}$ \\
\hline Salmo trutta genome assembly, chromosome: 15 & river trout & 34.2 & 34.2 & $85 \%$ & 36 & $100.00 \%$ & 66900148 & $\lfloor$ LR584415.1 \\
\hline PREDICTED: Gouania villdenowi patatin like phospholipase domain containing 4 (pnpla 4 ). In & blunt-snouted. & 34.2 & 34.2 & $85 \%$ & 36 & $100.00 \%$ & 2622 & $\underline{X M}-02846$ \\
\hline PREDICTED: Gouania willdenowi patatin like phospholipase domain containing 4 (pnpla4). Iranscript v... & biunt-snouted... & 34.2 & 34.2 & $85 \%$ & 36 & $100.00 \%$ & 2459 & $\underline{X M} 028465615$ \\
\hline Anabas tostudineus gonome assembly, chromosome: 15 & climbing-perch & 34.2 & 34.2 & $85 \%$ & 36 & $100.00 \%$ & 21921250 & LR132040.1 \\
\hline Govania willdenowi genome assembly, chromosome: 2 & blunt-snouted... & 34.2 & 34.2 & $85 \%$ & 36 & $100.00 \%$ & 1384883 & LR132002.1 \\
\hline
\end{tabular}

Figure 2. The NCBI (National Biotechnology Information Center) result for nucleotide sequence "GGATGTCTATTGAGTGACAA" [13]. 
codes of Danio RERIO [11]. Another interesting result of NCBI is Timema. The longest known asexual period for Timema, including two species that have not engaged in sexual reproduction for a million years. Their eggs are about two $\mathrm{mm}$ long. One of the species of Timema is striped, which also shows camouflage function [12]. Asexuality in animals is rare, and the Timema-insect lineage that evolved without sex has been proven to have survived for centuries and even Timema reproduces asexually [13].

\section{Conclusions}

The most widely used number digit system today is decimal. But in this work, the square root of two numbers has been converted from decimal base system to binary number base system. Both the common feature of binary numbers (0 or 1) and the square root of two contain two numbers [14]. When the digits of the Euler number after the comma are converted from the decimal (10) number base system to the binary (2) number base system, they correspond to the number " 55 " in the Fibonacci series $(0,1,1,2,3,5,8,13,21,34,55 \ldots)$ [4]. Likewise, in this research, binary (2) number base system is used, too.

Firstly, the results of this research can be summarized as obtaining the number of root two after the comma through the chemical structure of the genetic codes. Secondly, the root two digits after the comma can be thought of as an indicator of genetic codes. One of the results of both Biochemistry and Mathematics common features is the NCBI blast results. Because these include both bony fish and in particular the DANIO RERIO. Zebra fish are an excellent favorite example used in many studies related to Biochemistry and genome [3]. One of the common NCBI results of pi numbers and Euler numbers with the square of the speed of light is Zebra fish [3] [8]. Let alone this result, NCBI result for CAAT Box and TATA Box also consist of bony fishes (Remember, Zebra fish are kind of bony fish, too) [15]. Finally, the calculation results of the square of two numbers with genetic codes [especially (A) Adenine, (T) Thymine, (C) Cytosine, (G) Guanine and (U) Uracil] are related to both Biochemistry and Mathematics. In short, the digits of the square root of two after the comma can be attributed not only to numbers in Mathematics, but also to genetic codes in Biochemistry. In summary, this similarity may be the beginning of the mutual relations of the sciences on the basis of the Quantum Perspective Model. That is, genetic codes can be taken as a small unit of analysis from the same perspective as mathematical numbers.

\section{Conflicts of Interest}

The author declares no conflicts of interest regarding the publication of this paper.

\section{References}

[1] https://apod.nasa.gov/htmltest/gifcity/sqrt2.1mil 
[2] Ölmez, T. (2020) Is There an Aesthetics in Golden Ratio as Regards to the Common Cis-Regulatory Elements versus to Atomic Numbers of Elements with Respect to Quantum Perspective Model? Neurology and Neuroscience Reports, 3, 1-4.

[3] Köklü, K. (2019) A Quantum Perspective Model to Genetic Codes through Various Sciences. NeuroQuantology, 17, 15-18. https://doi.org/10.14704/nq.2019.17.3.1974

[4] Ölmez, T. (2021) Is There a Similarity between Fibonacci Sequence and Euler's Number with Respect to Quantum Perspective Model? Global Journal of Science Frontier Research, 20, 33. https://doi.org/10.34257/GJSFRFVOL20IS9PG35

[5] Wieser, E.M., Holden, N., Coplen, B.T., Böhlke, J.K., Berglund, M., Brand, W.A., et al. (2013) Atomic Weights of the Elements 2011. Pure and Application Chemistry, 85, 1047-1078. https://doi.org/10.1351/PAC-REP-13-03-02

[6] Lodish, H., Berk, A., Zipursky, S.L., Matsudaira, P., Baltimore, D. and Darnell, J. (2018) Molecular Cell Biology. 6th Edition, Translation: Geçkil, H., Özmen, M., Yeşilada, Ö., Palme Publishing, New York, 294-302.

[7] Nirenberg, M., Leder, P., Bernfield, M., Brimacombe, R., Trupin, J., Rottman, F. and O'Neal, C. (1965) RNA Codewords and Protein Synthesis, VII. On the General Nature of the RNA Code. Proceedings of the National Academy of Sciences of the United States of America, 53, 1161-1168. https://doi.org/10.1073/pnas.53.5.1161

[8] Köklü, K. (2019) Is Relativity Theory Also Valid in Biogenetics and Mathematics? NeuroQuantology, 17, 53-58. https://doi.org/10.14704/nq.2019.17.3.1999

[9] Farrell, R.E. (2010) RNA Methodologies A Laboratory Guide for Isolation and Characterization. 4th Edition, Elsevier Academic Press, Amsterdam, 704-710.

[10] Basic Local Alignment Search Tool. https://blast.ncbi.nlm.nih.gov/Blast.cgi

[11] Danio Kyathit. https://en.wikipedia.org/wiki/Danio kyathit

[12] Timema. https://en.wikipedia.org/wiki/Timema

[13] Schwander, T., Henry, L. and Crespi, B.J. (2011) Molecular Evidence for Ancient Asexuality in Timema Stick Insects. Current Biology, 21, 1129-1134.

https://doi.org/10.1016/j.cub.2011.05.026

[14] https://owlcation.com/stem/Binary-Numbers

[15] Ölmez, T. (2021) With Respect to Quantum Perspective Model, Can Euler Numbers Be Related to Biochemistry? Global Journal of Science Frontier Research, 20, 7-14. https://doi.org/10.34257/GJSFRFVOL20IS9PG7 